thuốc. Hậu quả động kinh khang thuốc ảnh hưởng đển chất lượng sống của bệnh nhân. Phẫu thuật động kinh thùy thái dương có sang thương là phẩu thuật an toàn và hiệu quả. Để mang lại sự điều trị tối ưu cho bệnh nhân, thây thuốc Thần Kinh nển giới thiệu sớm bệnh nhân đến những trung tâm phẫu thuật động kinh đánh giá và có phương pháp điều trị thích hợp nhất.

Các từ viết tắt: HS: Hippocampal Sclerosis

MRI: Magnetic Resonance Imaging

3T: 3 Tesla

\section{TÀI LIÊU THAM KHẢO}

1. Asadi-Pooya A. A., Ashjazadeh N., et al (2014), "Management of epilepsy in resourcelimited areas: Establishing an epilepsy surgery program in Iran", Med J Islam Repub Iran, 2014; $28(1): 24$.
2. Lim K. S., Ahmad S. A. B., Narayanan V., Rahmat K., et al (2017), "Level 4 comprehensive epilepsy program in Malaysia, a resource-limited country", Neurology Asia 2017; 22(4), pp. $299-305$.

3. Rocque B., Davis M., McClugage S. G., et al (2018), "Surgical treatment of epilepsy in Vietnam: program development and international collaboration", Neurosurg Focus 45 (4):E3, pp. 1-6.

4. Shih Y. H., Lirng J. F., Yen D. Y., Ho D. M. T. (2003). Surgery of intractable temporal lobe epilepsy presented with structural lesions. J Chin Med Assoc. 2003;66(10); pp. 565-571.

5. Sen $A_{.}$, Jette N., Husain M., Sander J. W. (2020), "Epilepsy in older people", The Lancet, Volume 395, ISSUE 10225, pp. 735-748

6. Wiebe S., Girvin J. P., Blume W. T., Elisasziw (2001), "A randomized, controlled trial of surgery for temporal-lobe epilepsy", The New England Journal of Medicine, Volume 345, Number 5, pp. 311-318.

\title{
ĐÁNH GIÁ TÁC DỤNG VÔ CẢM VÀ GIẢM ĐAU SAU MỔ CỦA GÂY TÊ TỦY SỐNG BẰNG BUPIVACAIN KẾT HỢP VỚI CÁC LIỀU MORPHIN KHÁC NHAU TRONG PHẪU THUÂTT CHẤN THƯO'NG CHI DƯớI
}

\author{
Dương Đức Phúc*, Công Quyết Thắng**, Lưu Quang Thùy***
}

\section{TÓM TẮT}

Mục tiêu: So sánh tác dụng vô cảm và giảm đau sau mổ của GTTS bằng $8 \mathrm{mg}$ bupivacain $0.5 \%$ kết hợp với $100 \mathrm{mcg}, 200 \mathrm{mcg}, 300 \mathrm{mcg}$ morphin trong phẫu thuật chấn thương chi dưới tại bệnh viện Quân Y 105 từ tháng 11/2018 đến tháng 04/2019. Phương pháp nghiên cứu: Thử nghiệm lâm sàng, tiến cứu, có nhóm so sánh. Bệnh nhần được chia vào 03 nhóm ngẫu nhiên: Nhóm I gồm 40 bệnh nhân được GTTS bằng bupivacain liều $8 \mathrm{mg}$ kểt hợp với morphin $0,10 \mathrm{mg}$. Nhóm II gồm 40 bệnh nhân được GTTS bằng bupivacain liều $8 \mathrm{mg}$ kết hợp với morphin $0,20 \mathrm{mg}$. Nhóm III gồm 40 bệnh nhân được GTTS bằng bupivacain liêu $8 \mathrm{mg}$ kết hợp với morphin $0,3 \mathrm{mg}$. Kết quả nghiên cứu: Thời gian vô cảm của 3 nhóm kéo dài và gần như nhau, với nhóm I, II và III là: ở mức $\mathrm{T}_{12}$ là $140 \div 235$ phút; ở mức $\mathrm{T}_{10}$ là $90 \div 190$ phút; ở mức $\mathrm{T}_{6}$ là $65 \div 135$ phút, sự khác biệt không có ý nghĩa thống kê với $p>0,05$. Nhóm III dưng liều $0,3 \mathrm{mg}$ morphin có thời gian giảm đau sau mổ dài nhất là: $29,87 \pm 7,00$ giờ, tiếp đó nhóm II dùng liều $0,2 \mathrm{mg}$ morphin là $22,33 \pm 4,44$ giờ và thấp nhất là nhóm I dùng liều $0,1 \mathrm{mg}$ morphin $18,28 \pm 3,86$ giờ, sự khác

*Bệnh viện Quân Y 105,

**Đai hoc Y Hà Nọi,

***Bênh viện Việt Đức

Chịu trách nhiệm chính: Dương Đức Phúc

Email: duongducphuc@gmail.com

Ngày nhận bài: 18.11.2020

Ngày phản biện khoa hoc: 5.01 .2021

Ngày duyệt bài: 20.01.2021 biệt có ý nghĩa thống kê với $p<0,05$. Kết luận: Liều dùng morphin giảm đau: nên dùng liều $0,3 \mathrm{mg}$ vì tác dụng thời gian giảm đau kéo dài so với liêu $0,2 \mathrm{mg}$ hay $0,1 \mathrm{mg}$.

Từ khóa: gây tê tủy sông, bupivacaine, morphin

\section{SUMMARY}

EVALUATE THE NERVE BLOCK EFFECTS AND POSTOPERATIVE PAIN MANAGEMENT OF SPINAL ANESTHESIA BY BUPIVACAIN COMBINED WITH DIFFERENT MORPHIN DOSES IN LOWER EXTREMITY SURGERY

Objective: To compare the nerve block effects and postoperative pain management of spinal anesthesia by $8 \mathrm{mg}$ bupivacaine $0.5 \%$ combined with $100 \mathrm{mcg}, 200 \mathrm{mcg}, 300 \mathrm{mcg}$ morphine in lower extremity surgery at 105 Military Hospital from November 2018 to April 2019. Method: prospective randomized controlled trial interventional study. The patients were divided into three random groups: Group I included 40 patients who received $8 \mathrm{mg}$ bupivacaine combined with $0,1 \mathrm{mg}$ morphine. Group II consisted of 40 patients who received $8 \mathrm{mg}$ bupivacaine combined with 0,2 mg morphine. Group III consisted of 40 patients who received $8 \mathrm{mg}$ bupivacaine combined with $0,3 \mathrm{mg}$ morphine. Results: The nerve block time of 3 groups lasted nearly the same, with group I, II and III were: at T12 level was $140 \div 235$ minutes; at T10 was $90 \div 190$ minutes; at T6 level was $65 \div 135$ minutes, there was no statistically significant with $p>0.05$. Group III with $0.3 \mathrm{mg}$ morphine had the longest postoperative analgesia time: $29.87 \pm 7.00$ hours, followed by group 
II with $0.2 \mathrm{mg}$ morphine of $22.33 \pm 4.44$ hours and the lowest was group I with $0.1 \mathrm{mg}$ morphine of $18.28 \pm$ 3.86 hours, the difference had statistically meaning with $p<0.05$. Conclusions: Analgesia morphine dose: should apply dose of $0,3 \mathrm{mg}$ due to the longer lasting than dose of $0,2 \mathrm{mg}$ or $0,1 \mathrm{mg}$.

Keywords: spinal anesthesia, bupivacaine, morphine

\section{I. ĐĂT VẤN ĐỀ}

Gây tê tủy sống (GTTS) là phương pháp vô cảm chủ yếu trong phẫu thuật chi dưới. GTTS có ưu điểm là kỹ thuật đơn giản, giá thành thấp, hậu phẫu nhẹ nhàng và giảm đau sau mổ tốt. Bupivacain là thuốc tê có đặc điểm khởi tê nhanh, tác dụng kéo dài, cường độ mạnh, mềm cơ bụng và chi dưới kéo dài 2-5h nhưng có tác dụng không mong muốn là tụt huyết áp, mạch chậm... Các nhà gây mê luôn mong muốn giảm tác dụng phụ của thuốc tê để đảm bảo an toàn cho bệnh nhân nhưng vẫn đảm bảo vô cảm cho phẩu thuật. Để đáp ứng yêu cầu này cách tốt nhất là giảm liều thuốc tê và phối hợp với thuốc giảm đau khác. Một trong các thuốc có tác dụng hiệp đồng với thuốc tê là các thuốc giảm đau nhóm opiat: morphin, fentanyl, pethidin, sufetanyl... Hiện nay trên thế giới việc nghiên cứu phối hợp thuốc tê với morphin để vô cảm cho mổ và kéo dài thời gian giảm đau sau mổ đã mang lại hiệu quả cao. Katsuyuki Terajima và cộng sự cho rằng: phối hợp bupivacain với morphin trong GTTS để kéo dài thời gian giảm đau sau mổ, đơn giản, dễ thực hiện ở các bệnh viện và rẻ tiên hơn các kỹ thuật giảm đau khác đang sử dụng [1]. Ở Việt Nam, đã có nhiều đề tài nghiên cứu phối hợp bupivacain với morphin để GTTS trong mổ chấn thương chi dưới mang lại kết quả tốt. Tuy nhiên việc sử dụng morphin trong GTTS để phâuu thuật chấn thương chi dưới với liều bao nhiêu là tối ưu để đạt hiệu quả vô cảm trong phẫu thuật, giảm đau sau mổ kéo dài, hạn chế các tác dụng không mong muốn còn ít báo cáo chính thức. Chính vì vậy chúng tôi nghiên cứu đề tài: "Đánh giá tác dụng vô cám và giảm đau sau mô của GTTS bằng bupivacain kêtt hợp với các liều morphin khác nhau trong phẫu thuật chấn thương chi dưới"với mục tiêu sau: So sánh tác dụng vô cảm và giảm đau sau mổ của GTTS bằng $8 \mathrm{mg}$ bupivacain $0.5 \%$ kết hợp với $100 \mathrm{mcg}, 200 \mathrm{mcg}, 300 \mathrm{mcg}$ morphin trong phẫu thuật chấn thương chi dưới.

\section{II. ĐỐI TƯỢNG VÀ PHƯƠNG PHÁP NGHIÊN CỨU}

2.1 Đối tượng nghiên cứu: Bệnh nhân được chọn khi có đủ các tiêu chuẩn: BN có tinh thần tỉnh táo, đồng ý tham gia nghiên cứu. Tuổi từ 16 65 tuổi. Tình trạng sức khỏe ASA I, II. Cân nặng trên $40 \mathrm{~kg}$. Không có chống chỉ định với GTTS. Không có dị ứng với bupivacain và morphin.

Bệnh nhân bị loại trừ khỏi nghiên cứu khi có khó khăn trong giao tiếp, mắc bệnh động kinh hay tâm thần. Tiền sử hay hiện tại nghiện ma túy, từ chối tham gia nghiên cứu. Các trường hợp có tai biến, biến chứng về phẫu thuật và gây mê trong và sau mổ: chảy máu nhiều, tụt huyết áp nă̆ng, suy hô hấp... Dự kiến mổ kéo dài > 150 phút hoặc không đồng ý tiếp tục tham gia nghiên cứu.

2.2 Địa điểm và thời gian nghiên cứu:

- Địa điểm: khoa Gây mê hồi sức Bệnh viện Quân y 105.

- Thời gian: từ T11/2018 đến T4/2019.

2.3. Phương pháp nghiên cứu: Thử nghiệm lâm sàng, tiển cứu, có nhóm so sánh.

Chọn ngẫu nhiên theo phương pháp bốc thăm, thăm gồm 3 nhóm bằng nhau. Mỗi bệnh nhân sẽ tương ứng với một lân bắt thăm, bắt được thăm nào thì xếp vào nhóm đó và thực hiện đúng theo phương pháp đó. Mỗi nhóm được tiển hành nghiên cứu và thu thập số liệu như nhau. Nhóm I gồm 40 bệnh nhân được GTTS bằng bupivacain liều $8 \mathrm{mg}$ kết hợp với morphin 0,10mg. Nhóm II gồm 40 bệnh nhân được GTTS bằng bupivacain liều $8 \mathrm{mg}$ kết hợp với morphin $0,20 \mathrm{mg}$. Nhóm III gồm 40 bệnh nhân được GTTS bằng bupivacain liều $8 \mathrm{mg}$ kết hợp với morphin 0,3mg.

2.4 Xứ lý số liệu: Số liệu thu được xử lý bằng toán thống kê $y$ học bằng phần mềm SPSS 16.0. Sử dụng thuật toán $X 2$ để so sánh giữa 2 tỷ lệ biến định tính, test Anova và T.Student để so sánh các giá trị trung bình của biến định lượng khác nhau có ý nghĩa khi $p<0,05$.

\section{KẾT QUẢ NGHIÊN CứU}

\section{1 Đặc điểm chung của 3 nhóm nghiên cứu:}

Bảng 3.1. Đặc điểm về tuổi, chiều cao, cân nặng của ba nhóm nghiên cứu

\begin{tabular}{|c|c|c|c|c|}
\hline \multicolumn{2}{|c|}{ Thổng số } & Nhóm $\mathbf{I}(\mathrm{n}=40)$ & Nhóm II $(\mathrm{n}=40)$ & Nhóm III(n=40) \\
\hline \multirow{2}{*}{$\begin{array}{c}\text { Tuổi } \\
\text { (năm) }\end{array}$} & Min \pm SD & $39,05 \pm 15,59$ & $38,48 \pm 13,65$ & $40,30 \pm 14,76$ \\
\hline \multirow{2}{*}{$\begin{array}{c}\text { Chiều cao } \\
\text { (cm) }\end{array}$} & $\bar{X} \pm$ SD & $163,18 \pm 4,51$ & $16 \div 65$ & $17 \div 65$ \\
\cline { 2 - 5 } & Min $\div$ Max & $156 \div 170$ & $161,83 \pm 4,24$ & $163,63 \pm 3,89$ \\
\hline Cân nặng & $\mathrm{X} \pm$ SD & $57,40 \pm 5,48$ & $59,28 \pm 6,09$ & $158 \div 170$ \\
\hline
\end{tabular}




\begin{tabular}{|c|c|c|c|c|}
\hline$(\mathrm{kg})$ & Min $\div$ Max & $45 \div 65$ & $50 \div 69$ & $45 \div 68$ \\
\hline $\mathrm{P}$ & $\mathrm{p} 1>0,05$ & $\mathrm{p} 2>0,05$ & $\mathrm{p} 3>0,05$ \\
\hline
\end{tabular}

(p so sánh giữa ba nhóm, p1 so sánh giữa nhómI và nhóm II, p2 so sánh giữa nhóm I và nhómIII, p3 so sánh giữa nhóm II và nhóm III)

Nhận xét: Về tuổi, chiều cao, cân nặng, của ba nhóm tương đương và khác biệt không có ý nghĩa thống kê với p> 0,05. Như vậy các đối tượng ở các nhóm là gần giống nhau về tuổi, chiều cao, cân nặng.

3.2 Thời gian khởi phát mất cảm giác đau

Bảng 3.2. Thời gian khởi phát mất cảm giác đau T12, T10, T6 (phút)

\begin{tabular}{|c|c|c|c|c|c|}
\hline \multicolumn{2}{|c|}{ Thông số } & Nhóm I $(n=40)$ & Nhóm II $(n=40)$ & Nhóm III( $n=40)$ & $\mathbf{P}(\mathrm{p} 1, \mathrm{p} 2, \mathrm{p} 3)$ \\
\hline \multirow[b]{2}{*}{$\mathrm{T}_{12}$} & $\bar{X} \pm S D$ & $2,78 \pm 0,42$ & $2,95 \pm 0,75$ & $2,69 \pm 0,57$ & \multirow{2}{*}{$>0,05$} \\
\hline & $\operatorname{Min} \div \operatorname{Max}$ & $2 \div 3,5$ & $1,5 \div 4,5$ & $1,5 \div 3,5$ & \\
\hline \multirow[b]{2}{*}{$\mathrm{T}_{10}$} & $\mathrm{X} \pm \mathrm{SD}$ & $3,98 \pm 1,08$ & $3,57 \pm 0,77$ & $3,75 \pm 1,14$ & \multirow{2}{*}{$>0,05$} \\
\hline & Min $\div$ Max & $2,5 \div 6$ & $2 \div 5$ & $2 \div 6$ & \\
\hline \multirow{2}{*}{$\mathrm{T}_{6}$} & $\overline{\mathrm{X}} \pm \mathrm{SD}$ & $5,82 \pm 1,65$ & $5,29 \pm 1,27$ & $6,32 \pm 1,71$ & \multirow{2}{*}{$>0,05$} \\
\hline & Min $\div \operatorname{Max}$ & $3 \div 8$ & $3 \div 7$ & $3 \div 9$ & \\
\hline
\end{tabular}

Nhận xét: Thời gian bắt đâuu mất cảm giác ở các mức là không có sự khác biệt giữa các nhóm nghiên cứu.

\subsection{Thời gian vô cảm}

Bảng 3.3. Thời gian vô cảm T12, T10, T6 (phút)

\begin{tabular}{|c|c|c|c|c|c|}
\hline \multicolumn{2}{|c|}{ Thông số } & Nhóm I $(n=40)$ & Nhóm II $(n=40)$ & Nhóm III $(n=40)$ & $\mathbf{P}(\mathrm{p} 1, \mathrm{p} 2, \mathrm{p} 3)$ \\
\hline \multirow[b]{2}{*}{$\mathrm{T}_{12}$} & $X_{ \pm S D}$ & $178,58 \pm 28,83$ & $184,90 \pm 18,71$ & $185,43 \pm 27,89$ & \multirow{2}{*}{$>0,05$} \\
\hline & Min $\div$ Max & $140 \div 230$ & $155 \div 215$ & $145 \div 235$ & \\
\hline \multirow[b]{2}{*}{$\mathrm{T}_{10}$} & $X \pm S D$ & $133,25 \pm 28,51$ & $141,35 \pm 28,04$ & $130,65 \pm 25,16$ & \multirow{2}{*}{$>0,05$} \\
\hline & Min $\div$ Max & $90 \div 190$ & $95 \div 180$ & $90 \div 170$ & \\
\hline \multirow{2}{*}{$\mathrm{T}_{6}$} & $X \pm S D$ & $97,45 \pm 19,28$ & $101,52 \pm 18,45$ & $100,05 \pm 20,95$ & \multirow{2}{*}{$>0,05$} \\
\hline & Min $\div$ Max & $60 \div 130$ & $70 \div 125$ & $65 \div 135$ & \\
\hline
\end{tabular}

Nhận xét: Như vậy thời gian vô cã्̉m ở các mức không có sự khác biệt giữa 3 nhóm.

3.4 Mức độ giảm đau trong phẫu thựạt: Dùng thang điểm Abouleizh

\section{Bảng 3.4. Mức độ giảm đau cho phẫu thuật.}

\begin{tabular}{|c|c|c|c|c|c|c|}
\hline \multirow{2}{*}{ Mức độ } & \multicolumn{2}{|c|}{ Nhóm I $(\mathrm{n}=\mathbf{4 0})$} & \multicolumn{2}{|c|}{ Nhóm II(n= 40) } & \multicolumn{2}{c|}{ Nhóm III(n= 40) } \\
\cline { 2 - 7 } & $\mathbf{n}$ & $\mathbf{0}$ & $\mathbf{n}$ & $\mathbf{\%}$ & $\mathbf{n}$ & $\mathbf{\%}$ \\
\hline Tốt & 40 & 100 & 40 & 100 & 40 & 100 \\
\hline Trung binh & 0 & 0 & 0 & 0 & 0 & 0 \\
\hline Kém & 0 & 0 & 0 & 0 & 0 & 0 \\
\hline
\end{tabular}

Nhân xét: Số liệu cho thây tất cả các trường hợp trong ba nhóm nghiên cứu đều đạt mức độ giảm đau tốt, không có trường hợp nào phải dùng thêm thuốc giảm đau khác hay phải chuyển sang gây mê.

3.5 Thời gian giảm đau sau mổ. Thời gian giảm đau sau mổ tính từ khi kết thúc phâu thuật cho đến khi cảm giác đau xuất hiện với VAS $\geq 4$ điểm.

Bảng 3.5. Thởi gian giảm đáa sau mồ (giơ)

\begin{tabular}{|c|c|c|c|}
\hline Thời gian & Nhóm I $(\mathrm{n}=40)$ & Nhóm II( $\mathrm{n}=40)$ & Nhóm III(n = 40) \\
\hline $\mathrm{X} \pm \mathrm{SD}$ & $18,28 \pm 3,86$ & $22,33 \pm 4,44$ & $29,78 \pm 7,00$ \\
\hline Min $\div$ max & $12 \div 26$ & $16 \div 30$ & $20 \div 42$ \\
\hline $\mathrm{p}$ & $\mathrm{p} 1<0,05$ & $\mathrm{p} 2<0,05$ & $\mathrm{p} 3<0,05$ \\
\hline
\end{tabular}

Nhận xét: Thời gian giảm đau sau mố của nhóm I ngắn hơn nhóm II và dài nhất là nhóm III, sự khác biệt giữa ba nhóm có ý nghĩa thống kê với $p<0,05$. Điều này cho thấy tác dụng giảm đau sau mổ của và nhóm III kéo dài nhất, sau đến nhóm II và thấp nhất là nhóm I.

\section{BÀN LUẬN}

4.1 Tác dụng vô cảm của bupivacain khi kết hợp với morphin ở các liêuu khác nhau

Kết quả của nghiên cứu này cho thây thời gian khởi phát mất cảm giác đau ở các nhóm I, II, III ở T12 lần lượt là: 2,78 $\pm 0,42$ phút; 2,95 $\pm 0,75$ phút; $2,69 \pm 0.57$ phút, tương ứng với khoảng thời gian là: $2 \div 3,5$ phút; $1,5 \div 4,5$ phút và $1,5 \div 3,5$ phút. Tương tự với T10; T6. Sự khác biệt giữa ba nhóm nghiên cứu ở các mức khác nhau là không có ý nghĩa thống kê với $p>0,05$. Kết quả này cho thấy khi phối hợp bupivacain với morphin với liêu $0,1 \mathrm{mg}, 0,2 \mathrm{mg}$, 0,3mg để GTTS có tác dụng khởi tê như nhau. 
Kết quả của nghiên cứu này cũng giống với kết quả của của Cardoso MM [2] từ 2 đến 5 phút và cũng như nghiên cứu của Abboud TK [3]. Số liệu nghiên cứu của Phan Anh Tuấn từ 1,5 đến 3,5 phút, Trần Đình Tú, Nguyễn Văn Minh cũng cho kết quả tương tự [4], [5],[6]. Kết quả của nghiên cứu cho thây thời gian vô cảm ở bảng 4 thấp nhất là 60 phút ở mức $T_{6}$ và cao nhất là 235 phút ở mức $\mathrm{T}_{12}$. Ở mức $\mathrm{T}_{12}$ thời gian mất cảm giác của 3 nhóm lần lượt là: $178,58 \pm 28,83$ phút; $184,90 \pm 18,71$ phút; $185,43 \pm 27,89$ phút. Còn ở mức $T_{10}$ cho kết quả là: $133,25 \pm 28,51$ phút; $141,35 \pm 28,04$ phút ;130,65 $\pm 25,16$ phút và ở mức $T_{6}$ là: $97,45 \pm 19,28$ phút; $101,52 \pm$ 18,55 phút; $100,05 \pm 20,95$ phút. Ở cùng một mức, thời gian vô cảm ở 3 nhóm nghiên cứu không có sự khác biệt có ý nghĩa thống kê, điều này cho thấy khi gây tê kết hợp bupivacain với morphin với liều $0,10 \mathrm{mg}, 0,2 \mathrm{mg}$ và $0,3 \mathrm{mg}$ cho tác dụng vô cảm như nhau. Như vậy với thời vô cảm thu được từ nghiên cứu đảm bảo đủ cho phẫu thuật chấn thương chi dưới. Kết quả của nghiên cứu này giống với kết quả của Phan Anh Tuấn 121,83 $\pm 13,67$ phút [4], Đỗ Văn Lợi là 130,12 $\pm 15,02$ phút [7]. Nghiên cứu của chúng tôi về mức độ giảm đau trong mổ cho kết quả: $100 \%$ ở mức độ tốt, không có $B N$ nào phải chuyển phương pháp vô cảm khác hay phải dùng thêm thuốc giảm đau trong mổ vì chỉ dùng riêng bupivacain cũng đủ vô cảm để mổ, khi phối hợp với các thuốc dòng họ morphin thì chất lượng gây tê sẽ tốt hơn. Kết quả nghiên cứu này giống với kết quả của Đỗ Văn Lợi [7], nghiên cứu của Abboud TK, Cardoso MM, Katsuyki Terajima: 100\% ở mức độ tốt [3], [2], [1]. Như vậy khi phối hợp morphin với bupivacain để GTTS cho mức độ vô cảm tốt để mổ chấn thương chi dưới.

4.2 Đánh giá tác dụng giảm đau sau mổ. Chúng tôi thây thời gian giảm đau sau mổ của ba nhóm là khác nhau và sự khác biêt có ý nghĩa thống kê với $p<0,05$. Nhóm I ngắn hơn nhóm II (với $p<0,05$ ), nhóm I ngắn hơn nhóm III (với $\mathrm{p}<0,05$ ), nhóm II ngắn hơn nhóm III (với $\mathrm{p}<0,05)$. Khi bệnh nhân đau có nghĩa thuốc tê đã gần như hết tác dụng vì thời gian hồi phục dẫn truyền thần kinh sau tê tủy sống ngược với giai đoạn ức chế, vận động sẽ hồi phục sớm nhất sau đó đến cảm giác áp lực, cảm giác nhiệt, cảm giác sờ mó và cảm giác đau xuất hiện cuối cùng, một số bệnh nhân sau phẫu thuật đã vận động tốt nhưng vẫn không đau. Khi tiềm morphin vào khoang dưới nhện thì morphin là thuốc tan trong mõ ít nhất trong các thuốc ho morphin, trong dung dịch não tủy, morphin phân ly một lượng nhỏ gắn vào receptor phát huy tác dụng phân còn lại tồn tại trong dịch não tủy nên nồng độ morphin trong dịch não tủy giảm chậm, do vậy thời gian tác dụng kéo dài. Nghiên cứu của Abboud T.K kết hợp Bupivacain với $100 \mathrm{mcg}$ Morphin thấy thời gian giảm đau hoàn toàn là $18,6 \pm 0,9$ giờ [3]. Kết quả này tương tự như nhóm I của chúng tôi. Aboleish $E$ nghiên cứu phối hợp 0,2mg morphin với bupicacain gây tê tủy sống trên 34 bệnh nhân mổ lấy thai thì thời gian yêu cầu giảm đau trung bình sau mổ là 27 $\pm 0,7$ giờ [8]. Kết quả này tương tự như nhóm II của chúng tôi. Trong nghiên cứu của An Thành Công sử dụng morphin 0,3mg tủy sống trước mổ cho các phẫu thuật vùng bụng trên thấy thời gian giảm đau sau mổ là 4,59 $\pm 3,97$ giờ[9]. Kết quả này thấp hơn so với nhóm III của chúng tôi, nguyên nhân có thể do mổ vùng bụng trên bệnh nhân đau nhiều hơn. Ngày nay đã có nhiều phương pháp và kỹ thuật được áp dụng để giảm đau sau phẫu thuật bởi vì kiểm soát đau là một vấn đề được y học quan tâm như ngoài màng cứng, PCA, PCEA nhưng lại đắt tiền và kỹ thuật khó khăn so với gây tê tủy sống. Chính vì vậy viêcc kết hợp morphin với bupivacain trong gây tê tủy sống để giảm đau sau mổ đặc biệt là sau phẫu thuật chấn thương chi dưới trong nghiên cứu của chúng tôi hết sức có ý nghĩa trong thực tiễn, được áp dung thường xuyên taii bênh viển của chúng tôi vì hiệu quả giảm đau tốt và giá thành thấp.

\section{KẾT LUÂN}

- Thời gian khởi phát mất cảm giác đau ở mức $T_{12}, T_{10}, T_{6}$ của nhóm I, nhóm II và nhóm III gần như nhau. Ở mức $T_{12}$ từ $1,5 \div 4,5$ phút; ở mức T 10 là $2 \div 6$ phút; ở mức $T_{6}$ là $3 \div 9$ phút, sự khác biệt không có ý nghĩa thống kê với p> 0,05. Thời gian vô cảm của 3 nhóm kéo dài và gần như nhau, với nhóm I, II và III là: ở mức T 12 là $140 \div 235$ phút; ở mức $T_{10}$ là $90 \div 190$ phút; ở mức $T_{6}$ là $65 \div 135$ phút, sự khác biệt không có ý nghĩa thống kê với $p>0,05$. Mức độ vô cảm cho phẫu thuật của 3 nhóm giống nhau đều đạt loại tốt.

- Nhóm III dùng liều $0,3 \mathrm{mg}$ morphin có thời gian giảm đau sau mổ dài nhất là: $29,87 \pm 7,00$ giờ, tiếp đó nhóm II dùng liêu $0,2 \mathrm{mg}$ morphin là $22,33 \pm 4,44$ giờ và thấp nhất là nhóm $\mathrm{I}$ dùng liêu $0,1 \mathrm{mg}$ morphin $18,28 \pm 3,86$ giờ, sự khác biệt có ý nghĩa thống kê với $p<0,05$.

\section{TÀI LIÊU THAM KHẢO}

1. Katsuyki Terajima, Hidetaka Onodera, Masao Kobayashi, Hiroko Yamanaka, Takashi Ohno, 
Swiichi Konuma and Ruo Ogawa (2003). "Effcacy of Intrathecal Morphine for analgesia Following Elective Cesarean Section: comparison with Previous Delivery", J Nippon Med Sch 70 (4).

2. Cardoso MM, Carvalho JC, Amaro AR (1998) Small dose of intrathecal morphine combined with systemic diclofenac for posteoperative pain control after dilivery. Anesth Analog: 86: 538-541.

3. Abboud TK, Dror A, Mosaad P, Zhu J, Mantilla M, Swart F (1988), "Mini-dose intrathecal morphine for the relief of post- cesarean section pain: safety, efficacy, and ventilatory responses to carbon dioxide. Anesth Analg 67, pp. $137-41$.

4. Phan Anh Tuấn (2008), "Đánh giá tác dụng của Gây tê tủy sống băng bupivacain kết hợp morphin và bupivacain kết hợp fentanyl trong mổ chi dưới", Luận văn thạc sỹ y học, Học viện Quân y.
5. Trân Đình Tú (2006) "Sự kết hợp bupivacaine (Marcaine heavy 0,5\%) với morphine hydroclorid bằng phương pháp gây tê tuỷ sống để vô cảm trong mổ và giảm đau sau mô lấy thai". Báo cáo khoa hoc.

6. Nguyến Văn Minh và cs (2007) Nghiên cứu tác dụng giảm đau sau mổ của Morphine tủy sống trong mổ lấy thai.

7. Đố Văn Lợi (2007): "Nghiên cứu phối hợp Bupivacain với Morphin hoăc Fentanyl trong gây tê tuỳ sống để mổ lấy thai và giảm đau sau mô", Luận văn thạc sỹ y học. Trường đại học Y Hà Nội.

8. An Thành Công (2011), "Đánh giá tác dung giảm đau dự phòng sau mổ tầng bụng trên bằng phương pháp tiêm morphine tủy sống", Luân văn thạc sỹ y học, Trường Đại học Y Hà Nội.

\section{NGHIÊN CỨU ỨNG DỤNG PHƯƠNG PHÁP GÂY TÊ NGOÀI MÀNG CỨNG ĐỂ GIẢM ĐAU CHUYỂN DA CHO SẢN PHU SINH THƯỜNG TẠI BỆNH VIỆN SẢN-NHI TỈNH QUẢNG NGÃI}

\section{TÓM TẮT}

Đắt vấn đề: Hiện nay, phương pháp giảm đau chuyển dạ bằng gây tê ngoài màng cứng được áp dung tại nhiều bệnh viện Phụ sản, đem lại nhiều lợi ích cho sản phụ và làm giảm tỷ lệ sinh mổ. Bệnh viện chúng tôi đang sử dụng phương pháp gây tê ngoài màng cứng bằng Bupivacain phối hợp với Fentanyl để giảm đau trong chuyển da nhưng chưa được đánh giá, chúng tôi muốn xem hiệu quả tác dụng giảm đau của phối hợp hai loại thuốc này. Muc tiếu: Đánh giá hiệu quả giảm đau, các tác dụng k̂̉ông mong muốn và mức độ hài lòng của sản phụ khi lựa chọn phương pháp gây tê ngoài màng cứng trong chuyển dạ sinh thường bằng phối hợp thuốc Bupivacain và Fentanyl. Đối tượng và phướng pháp nghiên cứu: Nghiên cứu cắt ngang mô tả chon sản phụ từ 18-40 tuổi, có chỉ định sinh thường, thuộc nhóm ASA I, II, đồng ý tham gia nghiên cứu và không có chống chỉ đinh gây tê ngoài màng cứng từ tháng 01 đến tháng 10 năm 2020 tại Bệnh viện Sản-Nhi tỉnh Quảng Ngãi. Kết quả: 326 sản phụ, chiều cao trung bình là 159,07 $\pm 7,71 \mathrm{~cm}$ và cân nặng trung bình là $60,04 \pm 7,59 \mathrm{~kg}$. Hiệu quả giảm đau trong chuyển dạ: Thời gian khởi tê trung bình là $5,77 \pm 1,35$ phút. Thay đổi điểm VAS: trước khi gây tê điểm VAS trung bình của sản phu là $7,15 \pm 1,28$, tương ứng mức độ đau nhiều và rất nhiều; sau 5 phút gây tê và trong các giai đoạn còn lại của cuộc chuyển dạ, điểm VAS trung bình đều <4. Tác dụng không mong muốn: Phương pháp chưa ghi nhận

${ }^{1}$ Bệnh viện Sản-Nhi tỉnh Quảng Ngãi

Chịu trách nhiệm chính: Nguyển Đình Tuyến

Email: nguyendinhtuyen889@gmail.com

Ngày nhận bài: 13.11.2020

Ngày phản biên khoa hoc: 6.01.2021

Ngày duyệt bài: 19.01.2021

\section{Nguyễn Đình Tuyến ${ }^{1}$, Nguyễn Tiến Dũng1}

ảnh hưởng đến tim thai trong chuyển dạ; không ảnh hưởng đến tần số tim cũng như thay đổi $\mathrm{SpO}_{2}$, huyết áp của sản phụ. Ghi nhận một số tác dụng không mong muốn nhứng không ảnh hưởng đến tổng trạng sản phu trong cuộc đẻ như: lanh run, tưt huyết áp, nôn, bí tiểu, ngứa, đau đầu. Tỷ lệ sản phụ rất hài lòng là $30,68 \%$. Kết luân: Phương pháp duy trì giảm đau trong các giai đoạn của quá trình chuyển dạ đều rất tốt, thể hiện: trước khi gây tê điểm VAS trung bình đều $>7$, sau khi khởi tê điểm VAS trung bình ở các giai đoạn của chuyển da đều <4. Phương pháp chưa ghi nhẩn ảnh hưởng tới hô hấp của sản phư và tân số tim thai. Tỷ lệ tác dụng không mong muốn ít. Tỷ lệ sản phụ hài lòng cao.

Tư khóa: Gây tê ngoài màng cứng, giảm đau chuyển dạ, Bệnh viện Sản-Nhi tỉnh Quảng Ngãi.

\section{SUMMARY}

\section{RESEARCH ON EPIDURAL ANESTHESIA FOR PAIN RELIEF IN LABOR AT QUANG NGAI HOSPITAL FOR WOMEN AND CHILDREN}

Background: Epidural analgesia is a commonly used method of pain relief in labor in many obstetrics hospitals, brings various benefits and avoids unnecessary cesarean sections. Epidural anesthesia with Bupivacain and Fentanyl has been used during labor in our hospital and not evaluated yet. Objectives: To evaluate the effectiveness of pain relief, adverse effects and maternal satisfaction with epidural analgesia during labor. Methods: This was a cross-sectional study on pregnant women reporting from January to October 2020 at Quang Ngai Hospital for Women and Children. The woman aged 18-40 years, classified as American Society of Anesthesiologists score I and II who requested epidural analgesia in active labor were taken for this 